\title{
A Brief Overview of How Male Medicine Co-Opted the Midwife's Role in the Birth Process
}

\author{
Leonard F. Vernon \\ Sherman College of Chiropractic, Spartanburg, SC, USA \\ Email: drvernonchiro@aol.com
}

Received 31 July 2015; accepted 15 September 2015; published 18 September 2015

Copyright (C) 2015 by author and Scientific Research Publishing Inc.

This work is licensed under the Creative Commons Attribution International License (CC BY).

http://creativecommons.org/licenses/by/4.0/

(c) (i) Open Access

\section{Abstract}

The term medicalization has been defined as the process by which non-medical issues come to be defined and treated as medical problems. There are no better examples of this than pregnancy and childbirth. Prior to the intervention of physicians and hospitals, most females delivered unassisted or assisted by a relative or a midwife who usually had no formal education. As long as this remained the practice, pregnancy could not become a medical procedure. Through systematic changes, discussed in detail herein, this primarily female-oriented event involving family and amateur aids would come to be dominated by males who were the sole legally authorized providers of obstetrical care [1]. The increasing cultural authority of medicine facilitated the transfer of home delivery to hospital delivery and changed normal birth into a surgical procedure. This paper will examine the history of obstetrics and how a profession comes to redefine a normal life event as a disease state.

\section{Keywords}

Midwife, Obstetrics, Pregnancy, Hospitals

\section{Introduction}

By the mid 1800's, industrialization and urbanization had taken their toll on the working class population and had placed many in poverty. Overcrowded tenements with abysmal sanitation helped to contribute to a precipitous increase in infant mortality.

Increasing knowledge of how disease is spread, the growing influence of the infectious theory of disease, and changes in sanitation conditions in America's cities significantly reduced infant mortality rates in the latter part 
of the century [2]. This reduction in infant mortality helped bolster the role of medicine in the birthing process; however, this process nonetheless remained one that occurred in the home and usually with a lay midwife in attendance. As the all-male area of obstetrics continued to gain cultural authority, a receptive public was beginning to accept the new concept of pregnancy and delivery as disease states. By 1915 , only approximately $40 \%$ of births were attended by a midwife [3].

The decline in the use of midwives had already begun in the mid 1800's when it became in vogue for upper and middle class women to have their own "regular" physician (as opposed to those from other schools of medicine such as Homeopathy) for obstetrical care. The acceptance of these formally trained male physicians was not universal; the majority of the general citizenry regarded the idea of a male examining a female (trained or not) as "grossly indecent." By 1935, while home births were still popular (only 37\% of all births were performed in a hospital), only approximately $11 \%$ of births were attended by midwives, the majority of which were concentrated in the rural south where the divide was geographic, economic, and racial. In the same year, midwives attended only $4.5 \%$ of all Caucasian births but 54\% of all nonwhite births [3]. In her book Catching Babies, author Charlotte Borst said "Americans of the progressive era came to view scientific and other specialized knowledge as the province of professionals, and the birthing room became the arena for demonstrating the goals of the new scientific professional.” [4]. The medical profession demonstrated such dominance that by the 1960's nearly 99\% of the babies in the Western Hemisphere were delivered by physicians, of whom more than 93\% were male [5]. With this monopolization came the end of the home birth, and by 1968, 98.5\% of all deliveries in the United States were performed in a hospital [6]. The French philosopher Michel Foucault said it best: "Medicine's cultural authority is not dependent on efficacy alone but on the ability to re-conceptualize a phenomenon as 'medical' and an acceptance of the conceptualization by the public" [7]. And so the public did.

\section{Gaining Control}

What had previously been a social event solely in the domain of females was appropriated by a male-dominated profession; obstetrics thus requires a detailed examination herein. The process by which this monopolization took place was gradual and was assisted by cultural factors such as urbanization, the building of hospitals, and the political power gained by medical associations [8]. However, before any change could occur, it would first be necessary for men to obtain the acceptance of society to be present at a birth and then redefine the once natural process of birth as an event that required professional medical assistance. The use of the lay midwife was among the first institutions to be eliminated by this change.

Midwifery in Colonial America began as an extension of European practices in which there were formal training programs for midwives. The absence of any such programs left the training of additional midwives to those who resided in Colonial America. Training was not in a formal setting but more of an on-the-job learning experience similar to an apprenticeship. This was also a time when the profession of medicine, while well established in Europe, was virtually non-existent in the early colonies [9]. Historical records have recorded some early colonial midwives including Bridget Fuller (d. 1664) who practiced in the Massachusetts Bay Colony and a "Mrs. Wiat" of Dorchester (d. 1705) who is said to have attended over 1000 births. Others, such as Ruth Barnaby (1664-1765) and Elizabeth Phillips (1685-1761), practiced for over forty years. Historical records indicate that Elizabeth Phillips was trained in London before continuing her practice in Boston. In the Dutch colony of New Netherland, the colonists constructed a building for the official midwife. This position was held by "Mrs. Trynje" in 1644 and Hellegond Joris in 1655. In 1658, the Dutch councilors of New Amsterdam appointed midwife Hilletje Wilbruch to oversee a new hospital. The English would later take over New Amsterdam and rename it New York. Midwifery remained prominent in the area [10].

The midwife held special social status within early African American slave population communities. Nearly every large Southern plantation, particularly in South Carolina, had at least one knowledgeable midwife/healer. During Reconstruction, legislative efforts by organized medicine to put Black lay midwives, or "granny midwives" as they were sometimes pejoratively referred to outside the birthing business, were only minimally successful, and rural women of the South (both black and white) would continue to receive essential healthcare services from these women into the 19th, 20th, and 21st centuries [11].

Medicine gradually gained control of the birthing process and eliminated the lay midwife. The first step in this process would be the establishment of medicine as a profession. Once this was accomplished, the formation of professional associations with lobbying power in individual states would become an effective method for 
controlling licensure and limiting the activities of midwives as well as placing legal sanctions on them. All of this occurred while females were barred from entering the profession of medicine.

An attempt to break through this barrier of sexual dominance occurred in 1850 with the founding of the Women's Medical College of Pennsylvania, the first medical institution in the world established to train women in medicine and offer them the M.D. degree. While the plan may have seemed like a good one, the recruitment of faculty would prove to be more difficult than originally thought, primarily due to threats made against any physician who would assist a female in obtaining a medical education. For example, in 1859, the Medical Society of the County of Philadelphia passed "resolutions of excommunication" that would be brought "against every physician who should teach in a medical school for women and every one (sic) who should consult with a women physician or with a man teaching a women medical student.” Similar activity occurred in Massachusetts: the Massachusetts Medical Society refused to admit legally licensed women physicians into their organization during an era when the professional associations held the weight of credibility [12]. It was clear from these actions that competition was the primary factor in inhibiting females from entering the medical profession and not a fear of incompetence. Similarly, the elimination of midwives was under the guise of protecting the public from incompetent practitioners. The grossly disingenuous nature of this assertion is clearly evident due to the fate of an 1884 bill that was introduced in the New York state legislature to grant a charter to a college that was planning on training midwives to ostensibly give the public access to trained midwives and thus eliminate the risk posed by lay midwives. Members of the New York Academy of Medicine promptly had the bill killed [13] These methods have been described by medical historians as "occupational displacement" [14].

\section{The Power of Medical Rhetoric}

This campaign of "occupational displacement” was successful in eliminating a significant number of deliveries by midwives, and by 1900, 50\% of all women in the US had physician-attended births [15]. Medicine's influence in government was also increasing, and with the aid of the government printing office, the dissemination of medical rhetoric took on an additional layer of authenticity to further minimize the role of the midwife in the birthing process. The 1913 publication of the educational pamphlet Prenatal Care, published by the United States Children's Bureau, was the first widespread distribution of printed material that completely re-conceptualized pregnancy as a medically problematic event. In the first three decades of the 20th century, Prenatal Care was distributed to over twenty-two million pregnant women. Barker argues convincingly that the medical rhetoric used in this and other publications played a significant role in helping to enhance medicine's cultural authority [16].

Defenders of such tactics would argue that publications such as Prenatal Care and the introduction of prenatal care as a routine procedure combined with the overall medicalization of pregnancy were responsible for reducing infant and maternal mortality. However, when the historical data are examined, there appears to be no link between the decrease in these deaths and the introduction of this care or medical interventions [17]. Reductions in such deaths in the 20th century are nearly entirely attributed to the elimination of post-surgical infection and the use of aseptic and antiseptic techniques. Moreover, recent scholarship has raised doubts regarding the relationship between prenatal care and low birth weight babies, which has long been viewed as a predictor of infant mortality. Data suggest that there has been no corresponding decrease in low birth weight babies despite a significant increase in the percentage of women receiving prenatal care; this calls into question the overall efficacy of medical prenatal care [18].

Historian John Burnham aptly called the period from the beginning of the twentieth century up to the late 1950s "American medicine's golden age." [19]. This was a period when physician incomes began to dramatically increase. With this came an increase in respectability as well as the ability to fund an organized political lobby. It was also the period in which specialty boards were organized to create a nearly exclusive club-like group. These boards also facilitated the education of young medical students and instructed the public about the special training of these physicians. The first specialty board examination was offered in ophthalmology in 1916 and was soon followed by otolaryngology in 1924. Not surprisingly, the third specialty board created was in the area of obstetrics and gynecology in 1930. This action was an attempt to eliminate the lay midwife, and (because membership in this specialty organization was limited to practitioners with practices that were $100 \%$ dedicated to women) it had the desired effect of eliminating other competitors as well. The family physician was among those denied access to the organization and its examination and diploma. Despite the size of his obstetrical prac- 
tice, the family doctor, who often as part of his routine practice included obstetrics, was eliminated from this exclusive group [20]. The outbreak of World War II also aided in establishing the validity of these boards. With the help of the American Medical Association, the political influence of which continued to grow, the military gave preference to "properly certified" physicians who were given a higher rank than general physicians. Stevens notes that this was a turning point for specialty boards with physicians who had a "healthy respect for the value of board certificates" [21].

\section{Men and Medicine Strengthen Their Grip on Women's Health}

The 1930's was a period during which the male-dominated profession of obstetrics and gynecology increased its influence by introducing technology and instrumentation with methods that appeared to be performed out of concern for and to benefit women. One example was the school of thought that all births should be performed via cesarean section. The reasoning for this was to "preserve" the genital tract in its original state. Eliminating the stretching of the vaginal area that occurs during birth would be "conducive to a happier marital state." [22]. This was also the period during which the "prophylactic forceps" began to be used with regularity. Not all practicing obstetricians agreed with the new methods of delivery, and many believed that the process of childbirth was a natural event and that less interference in the process was better for both the baby and mother. Of 223 United States hospitals surveyed in 1932, 37\% reported their incidence of forceps deliveries to be 20 percent or higher; this figure ranged up to $81 \%$ [23]. With this increased intervention came an increase in infant deaths from birth injuries. In 1937, Irving wrote in the New England Journal of Medicine "We have prophylactic forceps, prophylactic version, and even prophylactic rupture of membranes. It is not evident against what the prophylaxis is directed, unless it be against normal childbirth." [24].

The many new delivery "techniques" were enabled with the introduction of scopolamine, which, when combined with morphine, created a "twilight" sleep for the mother during delivery. Its other benefit was its ability to induce amnesia; thus, there was a very good chance that the patient would not remember the events even if the delivery were complicated. Rudolph Holmes, the obstetrician who introduced scopolamine to United States obstetrics, was so appalled by the use of forceps in deliveries that he later said "I wish to God I hadn't done it." [25]. He concluded: "The basic error has crept into the obstetric field that pregnancy and labor are pathologic entities, that childbearing is a disease, a surgical malady which must be terminated by some spectacular procedure. There is too insistent preachment by those who are defending a reign of terror, of promiscuous operative furor, on the argument that women have so degenerated that childbearing is a phase of pathologic anatomy." [26]. One study examined obstetric mortality among 8269 births to the European royal families from 1500 to 1930. For the 1600 births in the 1800's, neonatal mortality (under one month) was 32 per 1000 live births, a rate not equaled in the United States until 1937 [27]. It was clear that, for better or for worse, the natural process of childbirth (for which very little help was needed for thousands of years) was becoming a medical procedure and the belief in the pathologic nature of childbirth began to spread across the country. Political economist Lesley Doyal said "Childbirth has been transformed into 'clinical' crises and hence is regarded as a legitimate and important area for medical intervention.” [28].

Women, especially those with financial means, increasingly sought hospital births despite the potential dangers of surgery and anesthesia [29]. Increased demand for hospital birthing was also the result of a fear factor. What if the patient needed "operative interference"? As dangerous as this may be, it was even more dangerous when performed at home. The other reason many women may have begun to seek out hospital birthing was the increased use of anesthetic agents with the popular press touting "painless delivery," [30] and while nitrous oxide had been used in hospitals as well as during home deliveries in the 1920's [31], women were now warned that "new" methods of painless childbirth could be used only in up-to-date hospitals [32].

Another downside to hospital delivery was the surrendering of all autonomy to the physician and hospital. At home, the patient exerted some control over procedures and anesthesia administered by birthing attendants; in the hospital, women had no input into the drugs and procedures they received. Through the 1940s, hospital births frequently left women disillusioned and terrified, often contributing to psychiatric distress for extended periods after delivery. One woman wrote: "Months later I would scream out loud and wake up remembering that lonely labor room and just feeling no one cared what happened to me, not one kind reassuring word was spoken by nurse or doctor. I was treated as if I was an inanimate object.” [15]. Social psychologist Annadis Rudolfsdottir noted "...that the process of birth has become so mechanized that physicians forget that the cervix and vagi- 
na are sexual organs and not just a birth canal. As such, they are laden with connotations about women's modesty and sexuality which may be explicitly disregarded during the birth process, but can never be absent for women." [33]. By the beginning of the 1950's, women had all but completely surrendered the natural process of childbirth to a mechanized, male-dominated medical establishment.

\section{Women Fight Back}

The driving force behind the medicalization of pregnancy is the assumption of risk associated with either or both the mother and fetus [34]. The re-conceptualization of pregnancy as a time of risk and danger has given unprecedented power and authority to the medical profession. It is now perceived and overwhelmingly accepted that these medical professionals determine, control, and rectify potential or actual problems during childbirth. This shifting of control from pregnant women to doctors or other medical professionals brings with it increased power of experts at the expense of women [35]. Young argues that the process has led to "the appropriation by one subject of another subject's body, action or product of action.” He believes that physicians develop and control knowledge in three ways: 1) by defining pregnancy as a medical disorder, 2) by using medical instruments to understand the internal processes, and 3) through employing a medical setting, which discounts women's control of and expertise in their own pregnancy [36].

Historically, the medical treatment of women has been inferior to that for their male counterparts. Studies have previously demonstrated that compared with men, women receive somewhat less aggressive treatment during the early management of acute myocardial infarction [37] [38], and other studies have demonstrated gender bias in the management of serious, life-threatening diseases such as cardiovascular disease, lung cancer, and kidney failure [39]. As late as 1984, Oakley demonstrated this gender bias in the derogatory manner in which pregnant women were viewed. Pregnant women were perceived as deficient in that they lacked the education, responsibility, and intelligence necessary to take an active role in the management of their pregnancies. Women had no choice but to draw upon medical expertise following the conceptualization of pregnancy as a medical condition [40].

By the late 1970's, the feminist movement caused an increasingly hostile disenchantment with the medicalization of birth and with it a rebirth of midwifery. Women were demanding control over their bodies, how they would experience childbirth, where that birth would take place, and who would be in attendance to assist with the birth. It was also a period that included the partner in the birthing experience. The consumer control of medical decisions was increasing, and the profession of medicine would have to adjust [41] [42].

The definition of control in the context of childbirth varies somewhat from the standard definition of the word. This area is beyond the scope of this paper; however, an exhaustive examination of the subject of control in childbirth has been performed by Namey and Lyerly. In its simplest form, control was best described by one pregnant woman as “...the ability to accept or decline. Say 'yes' or 'no'. Just to be able to know what is going on. To have a doctor come in and say, 'Well I'm doing this'. It's better to say, 'Would you prefer we do this, or do you want to...?' Options, you have to have options. If not then you're not in control.” [43].

The Internet has aided in this increase in patient control and the demystification of medical expertise. The Internet has also caused an increase in lay skepticism about health professionals in general; this suggests a reduction in the power and status of the medical profession. While many in medicine view this as a negative, others have adapted to the Internet and see the Internet user as an informed patient. Use of the Internet for support does not entirely entail a turn away from medical care [44]. In the case of the female patients, it has empowered her to regain control of the reproductive process. Most women have attributed their motivation to search for information online to the lack of information provided by their health professional [45]. Although this is empowering to the pregnant patient, she must be cautioned that with the Internet's inability to vet information, it can also represent a source of misinformation: an estimated 136 million websites disseminate pregnancy-related information [46].

Due to new power and information sources, it is now possible to find midwives, hospitals with birthing centers, and a host of other consumer-friendly facilities and programs in which medical intervention is minimal or not present. The resurgence of the midwife has also occurred in part due to demand created through the Internet. Currently, there are there are three types of credentialed midwives in the United States: Certified Professional Midwives (CPMs), Certified Nurse-Midwives (CNMs), and Certified Midwives (CMs). While Nurse CNMs practice legally in all 50 US states and the District of Columbia, CPMs are legally authorized to practice in 28 
states. CMs practice legally in only three states. While CMs and CPMs are recognized as legal practitioners in some US states, direct access (without the referral or supervision of a medical physician) may not be available. Some attribute this to the archaic laws or marketplace competition that continues to pit medical doctors against midwives [47].

\section{Conclusions}

The history of how a male-dominated profession comes to dominate the female reproductive system is both fascinating and shocking. The rise in the cultural authority of the profession of medicine in the United States and the ability of the profession to establish itself as the sole experts in healthcare aided in the appropriation of childbirth and the process of delivery from the mother and midwife to the physician and the hospital. While the surrendering of her body for the sake of her baby is the common theme uttered when asked why women have so willingly capitulated to the procedures and requests of physicians, the truth is that they have little or no choice in the decision-making process.

The process of birth has now come full circle with an increasing demand for midwives and pending legislation in numerous states to again grant licensure to lay midwives. Many birth process and medicalization issues continue; however, larger pockets of the population are again welcoming natural childbirth.

\section{References}

[1] Szasz, T. (2007) The Medicalization of Everyday Life: Selected Essays. Syracuse University Press, Syracuse, 83.

[2] Bolduan, C. and Weiner, L. (1935) Infant Mortality in New York City One Hundred Years Ago. Journal of Pediatrics, 7, 55-59.

[3] Jacobson, P. (1956) Hospital Care and the Vanishing Midwife. Millbank Memorial Fund Quarterly, 34, $253-261$.

[4] Borst, C.G. (1995) Catching Babies: The Professionalization of Childbirth, 1870-1920. Harvard University Press, Boston, 1.

[5] (1966) International Federation of Genealogy and Obstetrics and the International Confederation of Midwives Maternity Care in the "World International Survey of Midwifery Practice and Training” (Report of a Joint Study Group), Pergamon, Oxford, London, New York, Toronto, Sidney, Paris, Braunchweig, 3.

[6] US Department of Health, Education and Welfare (1969) Vital Statistics of the United States. Volume I, Natality, US Government Printing Office, Washington DC, Table I-S, 1-20.

[7] Foucault, M. (1975) The Birth of the Clinic, Trans. Alan Sheridan-Smith. Vintage Books, New York.

[8] Gallagher, E.B. (1988) Modernization and Medical Care. Sociological Perspectives, 31, 59-87.

[9] Parkland School of Nurse Midwifery (2015) History of Midwifery in the US 05/28/2000. http://www.neonatology.org/pdf/midwifery.history.pdf

[10] Donegon, J.B. (1978) Women \& Men Midwives: Medicine, Morality, and Misogyny in Early America. Greenwood Press, Westport.

[11] Bonaparte, A.D. (2007) The Persecution and Prosecution of Granny Midwives in South Carolina, 1900-1940. PhD Dissertation, Vanderbilt University, Nashville, 178-181.

[12] Spencer, A.G. (1972) Woman's Share in Social Culture. In: Schneir, M., Ed., Feminism: The Essential Historical Writings, Vintage, New York, 269-285.

[13] Garrigues, H.J. (1898) Midwives. Medical News, February 19, 1898, 11.

[14] Brack, D.C. (1975) Displaced-The Midwife by the Male Physician. Women \& Health, 1, 18-24. http://dx.doi.org/10.1300/J013v01n06_04

[15] Leavitt, J.W. (1986) Brought to Bed: Childbearing in America, 1750-1950. Oxford University Press, New York.

[16] Barker, K.K. (1998) A Ship upon a Stormy Sea: The Medicalization of Pregnancy. Social Science and Medicine, 47, 1067-1076. http://dx.doi.org/10.1016/S0277-9536(98)00155-5

[17] Huntington, J. and Connell, F. (1994) For Every Dollar Spent: The Cost-Savings Argument for Prenatal Care. New England Journal of Medicine, 331, 1303-1307. http://dx.doi.org/10.1056/NEJM199411103311910

[18] Lantz, P. and Partin, M. (1995) Prenatal and Infant Health Indicators. Conference Papers, Volume 2, Institute for Research on Poverty Special Report Series, Indicators of Children's Well-Being, Child Education and Economic Security, May 1995, 3-32. http://www.irp.wisc.edu/publications/sr/pdfs/sr60b.pdf

[19] Burnham, J.C. (1982) American Medicine’s Golden Age: What Happened to It? Science, 215, 1474-1479. 
http://dx.doi.org/10.1126/science.7038876

[20] Starr, P. (1982) The Social Transformation of American Medicine. Basic Books, New York.

[21] Stevens, R. (1998) American Medicine and the Public Interest. University of California Press, Berkeley.

[22] Brown, W.E. (1930) The Trend of Modern Obstetrics. Journal of Iowa State Medical Society, 20, 550-553.

[23] White House Conference on Child Health Protection: Forceps and Cesarean Section, "Fetal, Newborn and Maternal Mortality”. D. Appleton-Century Co., New York, 1932.

[24] Irving, F.C. (1937) Maternal Mortality at the Boston Lying-In Hospital in 1933, 1934, and 1935. New England Journal of Medicine, 217, 693-695. http://dx.doi.org/10.1056/NEJM193710282171803

[25] (1936) Childbirth: Nature vs. Drugs. Time, 27, 32-36.

[26] Holmes, R.W. (1921) The Fads and Fancies of Obstetrics. American Journal of Obstetrics and Gynecology, 2, 225237.

[27] Peller, S. (1943) Studies on Mortality since the Renaissance. Bulletin of the History of Medicine, 13, 427-461.

[28] Doyal, L. (1995) What Makes Women Sick: Gender and the Political Economy of Health. BMJ, 311, 577. http://dx.doi.org/10.1136/bmj.311.7004.577

[29] de Kruif, P. (1936) Why Should Mothers Die? Ladies’ Home Journal, 53, 8.

[30] (1943) Childbirth without Pain. Newsweek, 21, 65.

[31] Day, J.L. (1926) The Use of Nitrous Oxide and Oxygen in Obstetrics in the Home. Anesthesia \& Analgesia, 5, 212213.

[32] (1943) Vogue Answers Questions on Childbirth. Readers’ Digest, 43, 33-35.

[33] Rudolfsdottir, A.G. (2000) I Am Not a Patient, and I Am Not a Child: The Institutionalization and Experience of Pregnancy. Feminism \& Psychology, 10, 337-350. http://dx.doi.org/10.1177/0959353500010003004

[34] Mitchell, L.M. (2001) Baby’s First Picture: Ultrasound and the Politics of Fetal Subjects. University of Toronto Press, Toronto.

[35] Parry, D.C. (2008) We Wanted a Birth Experience, Not a Medical Experience: Exploring Canadian Women’s Use of Midwifery. Health Care for Women International, 29, 784-806. http://dx.doi.org/10.1080/07399330802269451

[36] Young, I. (2001) Pregnant Embodiment. In: Welton, D., Ed., Body and Flesh: A Philosophical Reader, Blackwell Publishers, Oxford, 274-285.

[37] Yarzebski, J., Col, N., Pagely, P., Savageau, J., Gore, J. and Goldberg, R. (1996) Gender Differences and Factors Associated with the Receipt of Thrombolytic Therapy in Patients with Acute Myocardial Infarction: A Community-Wide Perspective. American Heart Journal, 131, 43-50. http://dx.doi.org/10.1016/S0002-8703(96)90049-6

[38] Kudenchuk, P.J., Maynard, C., Martin, J.S., Wirkus, M. and Weaver, W.D. (1996) Comparison of Presentation, Treatment, and Outcome of Acute Myocardial Infarction in Men versus Women. American Journal of Cardiology, 78, 9-14. http://dx.doi.org/10.1016/S0002-9149(96)00218-4

[39] van Wijk, C.M.T., van Vliet, K.P. and Kolk, A.M. (1996) Gender Perspectives and Quality of Care: Towards Appropriate and Adequate Health Care for Women. Social Sciences and Medicine, 43, 707-720. http://dx.doi.org/10.1016/0277-9536(96)00115-3

[40] Oakley, A. (1984) The Captured Womb: A History of the Medical Care of Pregnant Women. Basil Blackwell, Oxford.

[41] Rushing, B. (1993) Ideology in the Re-Emergence of North American Midwifery. Work and Occupation, 20 , 46-67. http://dx.doi.org/10.1177/0730888493020001003

[42] Inhorn, M.C. (2006) Defining Women’s Health: A Dozen Messages from More than 150 Ethnographies. Medical Anthropology Quarterly, 20, 345-378. http://dx.doi.org/10.1525/maq.2006.20.3.345

[43] Namey, E.E. and Lyerly, A.D. (2010) The Meaning of "Control” for Childbearing Women in the US. Social Science \& Medicine, 71, 769-776.

[44] Timmermans, S. and Oh, H. (2010) The Continued Social Transformation of the Medical Profession. Journal of Health and Social Behavior, 51, S94-S106. http://dx.doi.org/10.1177/0022146510383500

[45] Lagan, B.M., Sinclair, M. and Kernohan, G.W. (2011) What Is the Impact of the Internet on Decision-Making in Pregnancy? A Global Study. Birth, 38, 336-345. http://dx.doi.org/10.1111/j.1523-536X.2011.00488.x

[46] Pandey, S.K., Hart, J.J. and Tiwary, S. (2003) Women's Health and the Internet: Understanding Emerging Trends and Implications. Social Science and Medicine, 56, 179-191. http://dx.doi.org/10.1016/S0277-9536(02)00019-9

[47] Midwives Alliance of North America (2014) Legal Status of US Midwives. http://mana.org/about-midwives/legal-status-of-us-midwives 